Ariyanti, M. · C. Suherman · I.R.D. Anjasari · D. Sartika

\title{
Respon pertumbuhan bibit nilam aceh (Pogostemon cablin benth.) Klon sidikalang pada media tanam subsoil dengan pemberian pati beras dan pupuk hayati
}

\section{Growth of aceh patchouli (Pogostemon cablin benth.) 'sidikalang' clones on subsoil media that were treated by rice starch and biofertilizer}

Diterima : 11 Desember 2017/Disetujui : 18 Desember 2017 / Dipublikasikan : 30 Desember 2017

CDepartment of Crop Science, Padjadjaran University

\begin{abstract}
Media composition of topsoil remains a mainstay to favor the growth of patchouli because the content of mineral and organic matter is high. Along with its use, the availability of topsoil is reduced and it is necessary to search an alternative by using subsoil. Increasing the nutrient in subsoil is done by givingorganic fertilizer in form of starch of rice and biofertilizer. The experiment was conducted from June 2011 to September 2011 at the Experiment Station, Faculty of Agriculture, Padjadjaran University, Jatinangor, Sumedang Regency,West Java. The experimental design used Randomized Block Design consisted of 11 combination treatments and three replications. The treatments were top soil, subsoil+ $1,75 \mathrm{~g}$ of anorganic fertilizer, subsoil $+25 \mathrm{~g}$ of starch rice, subsoil $+50 \mathrm{~g}$ of starch rice, subsoil $+75 \mathrm{~g}$ of starch of rice, subsoil $+25 \mathrm{~g}$ of starch rice $+2.5 \mathrm{~g}$ of biofertilizer, subsoil $+50 \mathrm{~g}$ of starch rice, $+2.5 \mathrm{~g}$ of biofertilizer, subsoil $+75 \mathrm{~g}$ of starch rice $+2.5 \mathrm{~g}$ of biofertilizer, subsoil $+25 \mathrm{~g}$ of starch rice $+5 \mathrm{~g}$ of biofertilizer, subsoil $+50 \mathrm{~g}$ of starch rice, subsoil +5 $\mathrm{g}$ of biofertilizer, subsoil $+75 \mathrm{~g}$ of starch rice $+5 \mathrm{~g}$ of biofertilizer. The results of the experiment showed that the provision of $25 \mathrm{~g}$ of starch rice $+2.5 \mathrm{~g}$ biofertilizer on media subsoil influential good on the growth of patchouli especially on the increase of plant heigh, increase of number of leaves, increase of branches, leaf area, wet weight of plant, dry weight of plant, dry weight of root. The starch of rice contains $0.8 \% \mathrm{~N}, 0.29 \% \mathrm{P}_{2} \mathrm{O}_{5}, 0.07 \% \mathrm{~K}_{2} \mathrm{O}$, $1.48 \% \mathrm{CaO}, 1.14 \% \mathrm{MgO}, 10.04 \%$ C-organic.
\end{abstract}

\footnotetext{
Dikomunikasikan oleh Yudithia Maxiselly

Ariyanti, $\mathrm{M}^{1} \cdot$ C. Suherman ${ }^{1} \cdot$ I.R.D. Anjasari ${ }^{1} \cdot$ D. Sartika ${ }^{2}$

1) Staf Pengajar Departemen Budidaya Pertanian, Fakultas

Pertanian, Universitas Padjadjaran.

2) Alumni Program Studi Agroteknologi Fakultas

Pertanian, Universitas Padjadjaran

Korespondensi : mira. ariyanti@unpad.ac.id
}

Keywords : Patchouli, subsoil media, rice starch, biofertilizer

Sari Media tanam berupa topsoil masih menjadi andalan untuk mendukung pertumbuhan tanaman nilam karena kandungan mineral dan bahan organiknya yang tinggi. Seiring dengan pemanfaatannya, ketersediaan topsoil semakin berkurang dan dirasa perlu untuk mencari alternatif lain yaitu dengan memanfaatkan subsoil. Peningkatan unsur hara dalam subsoil dilakukan dengan cara pemberian pupuk organik berupa pati beras dan pupuk hayati. Percobaan dilakukan di Kebun Percobaan Fakultas Pertanian Universitas Padjadjaran Jatinangor pada Juni - September 2011. Penelitian menggunakan rancangan acak kelompok terdiri dari 11 kombinasi perlakuan diulang tiga kali. Perlakuan percobaan meliputi top soil, sub soil + pupuk anorganik N $1.75 \mathrm{~g}$, sub soil $+25 \mathrm{~g}$ pati beras, sub soil $+50 \mathrm{~g}$ pati beras, sub soil +75 g pati beras, sub soil $+25 \mathrm{~g}$ pati beras + pupuk hayati EMAS $2.5 \mathrm{~g}$, sub soil $+50 \mathrm{~g}$ pati beras + pupuk hayati EMAS $2.5 \mathrm{~g}$, sub soil $+75 \mathrm{~g}$ pati beras + pupuk hayati EMAS $2.5 \mathrm{~g}$, sub soil + $25 \mathrm{~g}$ pati beras + pupuk hayati EMAS $5 \mathrm{~g}$, sub soil + 50 g pati beras + pupuk hayati EMAS $5 \mathrm{~g}$, sub soil $+75 \mathrm{~g}$ pati beras + pupuk hayati EMAS $5 \mathrm{~g}$. Hasil penelitian menunjukkan bahwa pemberian $25 \mathrm{~g}$ pati beras + PHE 2,5 g pada media tanam subsoil menghasilkan pengaruh yang paling baik terhadap pertambahan tinggi, pertambahan jumlah daun, pertambahan cabang, luas daun, bobot segar tanaman, bobot kering tanaman, dan bobot kering akar tanaman nilam. Pati beras mengandung $0.8 \% \quad \mathrm{~N}, 0.29 \% \quad \mathrm{P}_{2} \mathrm{O}_{5}, 0.07 \% \quad \mathrm{~K}_{2} \mathrm{O}$, $1.48 \% \mathrm{CaO}, 1.14 \% \mathrm{MgO}, 10.04 \%$ C-organik.

Kata kunci : Nilam, subsoil, pati beras, pupuk hayati 


\section{Pendahuluan}

Tanaman nilam di Indonesia hampir semuanya merupakan pertanaman rakyat. Umumnya dilakukan dalam bentuk perladangan berpindah dan input budidaya minimal, sehingga produktivitas tanaman dan mutu minyak umumnya rendah (Direktorat Jendral Bina Produksi Perkebunan, 2002 dikutip Nuryani dkk., 2007). Perlu adanya upaya perbaikan teknik budidaya terutama dalam hal pemilihan bibit nilam, persiapan media tanam dan pemupukan untuk meningkatkan produksi nilam. Salah satu jenis nilam yang baik adalah nilam Aceh klon Sidikalang. Nilam Aceh klon Sidikalang memiliki keunggulan dibandingkan dengan klon lainnya. Beberapa keunggulan nilam aceh klon sidikalang adalah toleran terhadap penyakit layu dan nematode, memiliki kadar minyak yang lebih tinggi, dan memiliki daya adaptasi yang luas (Nuryani, 2006).

Media tanam yang baik akan mampu mendukung pertumbuhan tanaman nilam secara optimal. Media tanam nilam umumnya masih memanfaatkan topsoil karena memiliki kandungan mineral dan bahan organik yang tinggi. Menurut Lestariningsih (2012), topsoil merupakan tanah yang lebih subur jika dibandingkan dengan subsoil, karena banyak mengandung bahan organik dan unsur hara.

Alternatif pengganti topsoil adalah subsoil dimana ketersediaannya di alam relatif banyak. Menurut Hidayat dkk. (2007), subsoil dapat menjadi alternatif untuk menggantikan peran topsoil sebagai media tanam untuk tanaman perkebunan di pembibitan, disebabkan subsoil relatif lebih banyak tersedia dan dijumpai dalam jumlah yang besar serta tidak terbatas di lapangan, dibandingkan dengan topsoil yang berangsur-angsur menipis dan sulit didapatkan karena terkikis akibat erosi atau penggunaan secara terus menerus sebagai media pembibitan.

Subsoil mempunyai nilai kesuburan yang lebih rendah dibandingkan topsoil dalam hal kandungan bahan organik dan unsur hara sehingga perlu adanya penambahan unsur hara dan bahan organik (Erwiyono, 2005). Media tumbuh berupa subsoil merupakan media yang miskin hara. Hal ini sesuai dengan pernyataan Hardjowigeno (2003) bahwa semakin ke lapisan bawah tanah kandungan bahan organiknya semakin berkurang sehingga tanah semakin kurus atau miskin hara.
Pemanfaatan pupuk organik dan pupuk hayati merupakan salah satu solusi memperbaiki kesuburan tanah dalam upaya memanfaatkan subsoil sebagai media tumbuh tanaman. Media subsoil + pupuk kandang (2:1), subsoil + pupuk kandang + pasir (2:1:1), topsoil+ pupuk kandang (2:1), topsoil + pupuk kandang + pasir (2:1:1), memberikan pertumbuhan yang baik pada setek lada, sehingga dapat digunakan dalam pembibitan setek lada (Martin dkk, 2015). Komposisi media tumbuh kompos TKKS + sub soil + pasir dengan perbandingan 3:1:1 dan pupuk $\mathrm{N}$ sebanyak $4 \mathrm{~g}$ urea/tanaman merupakan komposisi terbaik untuk mensubstitusi peran topsoil serta dapat menghasilkan pertumbuhan bibit yang jagur (Sitio dkk, 2015).

Penggunaan pupuk anorganik secara terus menerus dalam jangka waktu yang lama menimbulkan efek negatif bagi tanah tersebut diantaranya tanah menjadi keras sehingga tidak baik digunakan sebagai media tanam tanaman. Upaya yang dapat dilakukan adalah menentukan alternatif lain sebagai bahan campuran dengan pupuk hayati kaitannya dalam menunjang pertumbuhan tanaman yaitu dengan pupuk organik. Pupuk organik yang berasal dari limbah rumah tangga merupakan langkah baik dalam mewujudkan perkebunan nilam yang berkelanjutan dan ramah lingkungan. Limbah rumah tangga yang berpotensi dijadikan pupuk organik berupa limbah air cucian beras (leri). Pupuk organik mampu memperbaiki sifat fisik, kimia dan biologi tanah, serta mampu menyediakan senyawa karbon yang berfungsi memperbaiki sifat fisik dan biologi tanah (Hartatik dkk, 2015).

Peranan pupuk organik terhadap sifat fisika tanah antara lain adalah (a) memperbaiki struktur tanah karena bahan organik dapat "mengikat" partikel tanah menjadi agregat yang mantap, (b) memperbaiki distribusi ukuran pori tanah sehingga daya pegang air (water holding capacity) tanah menjadi lebih baik (Hakim, 2013). Leri mengandung C-organik tinggi (10.04\%) sehingga diharapkan dapat berperan dalam meningkatkan aktivitas mikroba. Perbaikan sifat fisik tanah sebagai akibat dari penambahan bahan organik juga dapat meningkatkan daya sangga air, agregasi, permeabilitas dan aerasi tanah (Siregar, 2000).

Aplikasi leri dianggap kurang efektif apabila diaplikasikan untuk budidaya tanaman secara besar-besaran. Salah satu upaya untuk membuat penggunaan leri menjadi lebih praktis 
adalah dengan membuatnya menjadi pati (berbentuk tepung). Pati beras mengandung $0.8 \% \mathrm{~N}, 0.29 \% \mathrm{P}_{2} \mathrm{O}_{5}, 0.07 \% \mathrm{~K}_{2} \mathrm{O}, 1.48 \% \mathrm{CaO}$, $1.14 \% \mathrm{MgO}, 10.04 \%$ C-organik dengan $\mathrm{C} / \mathrm{N}$ sebesar 13 (Hasil analisis laboratorium Ilmu Tanah Fakultas Pertanian Universitas Padjadjaran, 2011). Penggunaan pati beras yang dikombinasikan dengan pupuk hayati diharapkan mampu memenuhi kebutuhan unsur $\mathrm{N}$ bagi tanaman nilam.

C-organik yang terkandung dalam pati beras yaitu sebesar $10.04 \%$ diharapkan mampu membuat respirasi dalam tanah lebih baik sehingga aktifitas mikroorganisme dapat menjadi lebih aktif. Menurut Suwahyono (2011), mikroba yang ada di dalam biofertilizer yang diaplikasikan pada tanaman mampu mengikat nitrogen dari udara, melarutkan fosfat yang terikat di dalam tanah, memecah senyawa organik kompleks menjadi senyawa yang lebih sederhana, dan memacu pertumbuhan tanaman. Penggunaan pupuk hayati yang dikombinasikan dengan pati limbah cucian pertama beras dapat meningkatkan penyerapan hara terutama hara $\mathrm{N}$ bagi tanaman nilam.

Penelitian ini bertujuan untuk mengetahui pengaruh pemberian pati beras sebagai pengganti pupuk anorganik yang dikombinasikan dengan pupuk hayati dalam meningkatkan produksi tanaman nilam Aceh klon Sidikalang pada media tanam subsoil.

\section{Bahan dan Metode}

Percobaan dilakukan di Kebun Percobaan Fakultas Pertanian Universitas Padjadjaran Jatinangor, dengan ketinggian tempat $\pm 750 \mathrm{~m}$ dari permukaan laut, ordo tanah Inseptisol, tipe curah hujan C menurut klasifikasi Scmidt dan Fergusson. Waktu percobaan Juni - September 2011. Bahan yang digunakan adalah bibit setek tanaman nilam Aceh klon Sidikalang berumur 1 bulan, topsoil $(0-20 \mathrm{~cm})$ dan subsoil $(20-40 \mathrm{~cm})$, urea, SP-36 dan $\mathrm{KCl}$, pupuk hayati EMAS, dan pati beras.

Metode yang digunakan berupa metode eksperimen dengan rancangan acak kelompok (RAK) terdiri dari 11 kombinasi perlakuan diulang tiga kali. Perlakuan percobaan meliputi top soil (A), sub soil + pupuk anorganik N 1,75 $\mathrm{g}(\mathrm{B})$, sub soil $+25 \mathrm{~g}$ pati beras $(\mathrm{C})$, sub soil +50 $\mathrm{g}$ pati beras $(\mathrm{D})$, sub soil $+75 \mathrm{~g}$ pati beras $(\mathrm{E})$, sub soil + pupuk hayati EMAS 2,5 g + $25 \mathrm{~g}$ pati beras (F), sub soil + pupuk hayati EMAS 2,5 g + 50 g pati beras $(\mathrm{G})$, sub soil + pupuk hayati EMAS 2,5 $\mathrm{g}+75 \mathrm{~g}$ pati beras $(\mathrm{H})$, sub soil + pupuk hayati EMAS $5 \mathrm{~g}+25 \mathrm{~g}$ pati beras (I), sub soil + pupuk hayati EMAS $5 \mathrm{~g}+50 \mathrm{~g}$ pati beras (J), sub soil + pupuk hayati EMAS $5 \mathrm{~g}+75 \mathrm{~g}$ pati beras (K).

Peubah yang diamati adalah pertambahan tinggi tanaman, pertambahan jumlah daun, pertambahan jumlah cabang primer dan cabang sekunder, luas daun, bobot segar tanaman, bobot kering tanaman, bobot kering akar. Data peubah yang diperoleh dianalisis secara statistik dengan uji $\mathrm{F}$ pada taraf $5 \%$, apabila terdapat perbedaan antar perlakuan diuji lanjut Duncan pada taraf $5 \%$.

\section{Hasil dan Pembahasan}

Tinggi tanaman merupakan indikator pertumbuhan yang digunakan untuk melihat pengaruh lingkungan dan perlakuan yang diterapkan karena tinggi tanaman merupakan ukuran pertumbuhan yang paling mudah untuk dilihat (Sitompul dan Guritno, 1991). Tabel 1 menunjukkan bahwa pemberian pati beras baik dengan atau tanpa PHE (pupuk hayati emas) tidak berpengaruh terhadap pertambahan tinggi tanaman pada umur 4 MST (minggu setelah tanam). Hal ini menunjukkan bahwa pada awal pertumbuhan tanaman, karakter pertumbuhan lebih dipengaruhi oleh sifat genetis tanaman dibandingkan dengan perlakuan pemupukan. Keadaan ini berlangsung sampai dengan umur tanaman 8 MST, dimana pemupukan baik dengan pati beras maupun PHE tidak berpengaruh terhadap tinggi tanaman yang dihasilkan. Selain itu pupuk yang diberikan merupakan pupuk organik sehingga pengaruhnya tidak berpengaruh langsung terhadap pertumbuhan tanaman, dalam hal ini tinggi tanaman nilam.

Pengaruh yang berbeda dengan adanya pemberian pati beras dan PHE mulai tampak pada umur tanaman nilam 12 MST (umur tanaman 3 bulan). Pada umur tersebut terlihat bahwa pemberian $25 \mathrm{~g}$ pati beras yang dikombinasikan dengan $2.5 \mathrm{~g}$ PHE pada media tanam subsoil (F) menghasilkan pertambahan tanaman lebih tinggi dibandingkan perlakuan topsoil saja (A) dan perlakuan subsoil + pupuk anorganik $\mathrm{N}$ $1.75 \mathrm{~g}$ (B). Hal ini menunjukkan bahwa kombinasi pati beras dan PHE telah mampu membantu menyediakan unsur hara yang 
dibutuhkan oleh tanaman dalam mendukung pertumbuhan tinggi tanaman. Mikroorganisme yang terdapat dalam PHE telah mampu bekerja aktif untuk membantu menyediakan unsur hara yang dibutuhkan dalam mendukung pertumbuhan tinggi tanaman.

Tinggi tanaman dapat dijadikan indikator keadaan pertumbuhan yang baik karena adanya pertambahan meninggi yang normal maka dapat dikatakan bahwa hara yang disuplai dapat dimanfaatkan oleh tanaman secara optimal. Menurut Zulfitri (2005), tanaman yang lebih tinggi dapat memberikan hasil per tanaman yang lebih baik dibandingkan dengan tanaman yang lebih pendek. Hal ini dikarenakan tanaman yang lebih tinggi dapat mempersiapkan organ vegetatifnya lebih baik sehingga organ fotosintat yang dihasilkan akan lebih banyak.

Tabel 1. Pengaruh Pati Beras dan PHE pada Media Tanam Subsoil terhadap Pertambahan Tinggi Tanaman Nilam Aceh Klon Sidikalang pada Umur 4 MST, 8 MST, dan 12 MST

\begin{tabular}{cccc}
\hline \multirow{2}{*}{ Perlakuan } & \multicolumn{3}{c}{ Rata-rata pertambahan tinggi } \\
tanaman $(\mathrm{cm})$
\end{tabular}

Keterangan : Nilai rata-rata perlakuan yang ditandai dengan huruf yang sama pada kolom yang sama tidak berbeda nyata berdasarkan Uji Jarak Berganda Duncan pada taraf nyata 5\% ; MST = Minggu Setelah Tanam $;$ PHE $=$ Pupuk Hayati EMAS

Pengaruh penggunaan subsoil sebagai media tanam bibit nilam mulai terlihat pada 12 MST yaitu tampak pada perlakuan $\mathrm{F}$ (subsoil+ $25 \mathrm{~g}$ pati beras $+2.5 \mathrm{~g}$ PHE) dan tidak berbeda nyata dengan perlakuan lainnya kecuali perlakuan A, B, C dan D. Penggunaan $75 \mathrm{~g}$ pati beras yang ditambahkan pada media tanam subsoil menghasilkan pertumbuhan tinggi bibit nilam yang tidak berbeda nyata dengan perlakuan bersamaan dengan pupuk hayati. Hal ini dapat diartikan bahwa pada tingkat penggunaan pati beras sebanyak $75 \mathrm{~g}$ sebenarnya sudah dapat mensuplai unsur hara yang cukup bagi pertumbuhan bibit nilam. Selain itu pati beras dan pupuk hayati yang digunakan telah mampu menyuplai hara bagi tanaman dan memperbaiki tekstur dan keseimbangan biologi media tanam dengan baik sehingga proses fisiologi tanaman dapat berjalan lebih baik daripada perlakuan yang menggunakan media tanam topsoil (A).

PHE mengandung beberapa bakteri penting yaitu Azotobacter beijerinckii (bakteri penambat N- dan pemantap agregat), Azospirillum lipoverum (bakteri penambat N-bebas), Aeromonas punctate (bakteri pelarut $\mathrm{P}$ ), Aspergillus niger (fungi pelarut $\mathrm{P}$ pemantap agregat tanah) (PT. Bio Industri Nusantara, 2014). Bakteri tersebut berperan dalam menfiksasi $\mathrm{N}_{2}$ sehingga mampu dimanfaatkan lebih lanjut oleh tanaman. N dibutuhkan tanaman dalam mendukung pertumbuhan vegetatif tanaman. Pemberian $2.5 \mathrm{~g}$ PHE dan $25 \mathrm{~g}$ pati pati beras dianggap sudah mencukupi kebutuhan kebutuhan tanaman nilam. Subsoil dapat dijadikan salah satu alternatif media tanam selain topsoil 100\%. Subsoil yang dipupuk dengan pati beras dan PHE diharapkan dapat menggantikan media tanam topsoil $100 \%$ untuk penanaman bibit tanaman nilam. Hal ini tampak dengan adanya pengaruh positif dari perlakuan tersebut terhadap tinggi tanaman nilam Aceh klon Sidikalang. Menurut Simanungkalit et al., (2006) pemberian dosis pupuk hayati yang berlebihan akan menyebabkan terjadinya persaingan antar mikroba dalam memperoleh makanan sehingga akan berpengaruh terhadap kebutuhan nutrisi mikroba, akibatnya mikroba akan bekerja kurang optimal sehingga pengaruhnya terhadap tinggi tanaman juga kurang optimal.

Daun merupakan organ tanaman yang berperan dalam proses fotosintesis. Kecepatan pertumbuhan daun pada setiap tanaman akan berbeda tergantung pada sifat spesies tanaman dan lebih besar dipengaruhi oleh sifat genetik tanaman terutama pada masa awal pertumbuhan dan perkembangan tanaman. Kecepatan pertumbuhan daun tampaknya dapat dijadikan salah satu indikator dalam mengetahui kecepatan pertumbuhan tanaman terutama pada tanaman dimana daun sebagai organ targetnya, misalnya nilam.

Pertumbuhan daun juga dipengaruhi oleh faktor lingkungan dan teknik budidaya yang dilakukan terutama pemupukan. Kaitannya daun sebagai organ source sekaligus sink pada suatu siklus hidup tanaman. Tabel 2 menun- 
jukkan adanya perbedaan pertambahan jumlah daun pada setiap perlakuan pemberian PHE dan pati beras pada media tanam yang berbeda yaitu topsoil dan subsoil. Pada keadaan yang umum dilakukan yaitu penanaman pada media topsoil terlihat adanya fluktuasi pertambahan jumlah daun pada rentang waktu 4 MST, 8 MST dan 12 MST. Terjadi penurunan jumlah daun pada 8 MST (Tabel 2), hal ini dapat disebabkan beberapa faktor misalnya serangan hama dan penyakit, terjadi keguguran daun, adaptasi tanaman dan faktor lainnya.

Tabel 2. Pengaruh Pati Beras dan PHE pada Media Tanam Subsoil terhadap Pertambahan Jumlah Daun pada Umur 4 MST, 8 MST, dan 12 MST.

\begin{tabular}{cccc}
\hline \multirow{2}{*}{ Perlakuan } & \multicolumn{3}{c}{$\begin{array}{c}\text { Rata-rata pertambahan jumlah daun } \\
\text { (helai) }\end{array}$} \\
\cline { 2 - 4 } & $\mathbf{4 ~ M S T}$ & $\mathbf{8 ~ M S T}$ & $\mathbf{1 2 ~ M S T}$ \\
\hline $\mathrm{A}$ & $5.00 \mathrm{a}$ & $4.11 \mathrm{a}$ & $7.78 \mathrm{ab}$ \\
$\mathrm{B}$ & $4.56 \mathrm{a}$ & $4.44 \mathrm{a}$ & $5.67 \mathrm{a}$ \\
$\mathrm{C}$ & $5.00 \mathrm{a}$ & $4.78 \mathrm{a}$ & $6.89 \mathrm{ab}$ \\
$\mathrm{D}$ & $5.89 \mathrm{~b}$ & $5.44 \mathrm{abc}$ & $7.56 \mathrm{ab}$ \\
$\mathrm{E}$ & $5.89 \mathrm{~b}$ & $5.11 \mathrm{ab}$ & $7.78 \mathrm{ab}$ \\
$\mathrm{F}$ & $9.00 \mathrm{~d}$ & $7.33 \mathrm{~d}$ & $15.00 \mathrm{e}$ \\
$\mathrm{G}$ & $7.22 \mathrm{c}$ & $6.78 \mathrm{~cd}$ & $10.89 \mathrm{~cd}$ \\
$\mathrm{H}$ & $7.11 \mathrm{c}$ & $6.33 \mathrm{bcd}$ & $9.67 \mathrm{bc}$ \\
$\mathrm{I}$ & $8.56 \mathrm{~d}$ & $7.56 \mathrm{~d}$ & $14.44 \mathrm{e}$ \\
$\mathrm{J}$ & $7.78 \mathrm{c}$ & $7.11 \mathrm{~d}$ & $12.67 \mathrm{de}$ \\
$\mathrm{K}$ & $7.78 \mathrm{c}$ & $6.89 \mathrm{~cd}$ & $13.56 \mathrm{e}$ \\
\hline
\end{tabular}

Keterangan : Nilai rata-rata perlakuan yang ditandai dengan huruf yang sama pada kolom yang sama tidak berbeda nyata berdasarkan Uji Jarak Berganda Duncan pada taraf nyata 5\%, ; MST= Minggu Setelah Tanam $;$ PHE $=$ Pupuk Hayati EMAS

Jumlah daun kembali meningkat pada umur tanaman 12 MST. Keadaan ini juga terjadi pada semua perlakuan lainnya sehingga hal ini tampaknya dapat dikaitkan dengan sifat pertumbuhan daun pada tanaman nilam pada umumnya. Laju pertumbuhan tanaman yang maksimal dapat diperoleh apabila terdapat cukup banyak daun dalam tajuk untuk menyerap sebagian besar radiasi matahari yang jatuh ke atas tajuk tanaman (Gardner et al. 1991). Semakin banyak jumlah daun maka akan meningkatkan kemampuan daun untuk berfotosintesis.

Pemberian $25 \mathrm{~g}$ pati beras dikombinasikan dengan $2.5 \mathrm{~g}$ pupuk hayati pada tanaman nilam asal setek berumur 1 bulan yang ditumbuhkan pada media tanam subsoil (perlakuan F) menghasilkan pertumbuhan daun nilam terbanyak pada 4 MST, 8 MST dan 12 MST. Pemberian pati beras dan pupuk hayati (PHE) memberikan kontribusi unsur $\mathrm{N}$ yang dibutuhkan tanaman nilam untuk menumbuhkan daundaun baru. Pemberian kombinasi pupuk tersebut dapat memberikan alternatif lain dalam penggunaan media tanam selain topsoil yaitu subsoil dengan tingkat pertumbuhan tanaman yang lebih baik terutama dalam jumlah daun yang dihasilkan.

Tabel 3 menunjukkan bahwa bibit tanaman nilam yang ditumbuhkan pada media tanam subsoil yang diberi pupuk anorganik saja (pupuk N) nyata menghasilkan pertambahan cabang primer yang lebih rendah dibandingkan dengan yang ditumbuhkan baik pada media tanam topsoil saja maupun subsoil yang diberi pupuk hayati dan pati beras. Hal ini menunjukkan bahwa apabila akan menggunakan media tanam selain topsoil, maka pemberian pupuk anorganik saja tidak mencukupi untuk memenuhi kebutuhan unsur hara bibit tanaman nilam, khususnya dalam menumbuhkan cabang primer yang menjadi karakter pertumbuhan penting sebagai tempat tumbuhnya daun-daun baru. Percabangan tergantung pada faktorfaktor yang menguntungkan pertumbuhan vegetatif yang cepat, terutama kelembaban dan $\mathrm{N}$ yang cukup (Gardner et al. 1991).

Pemberian $25 \mathrm{~g}$ pati beras dikombinasikan dengan $2.5 \mathrm{~g}$ pupuk hayati pada tanaman nilam asal setek berumur 1 bulan yang ditumbuhkan pada media tanam subsoil (perlakuan F) menghasilkan pertumbuhan cabang terbanyak pada 8 MST dan 12 MST. Secara keseluruhan, kondisi pertambahan jumlah cabang primer nilam yang lebih baik mulai dari umur 4 MST sampai 12 MST adalah tanaman yang diberi perlakuan kombinasi pati beras dan PHE (F, G, H, I, J, dan K). Hal ini menunjukkan bahwa pati beras dan PHE yang digunakan telah mampu membantu pengadaan hara bagi tanaman sehingga lebih tersedia bagi tanaman pada media tanam subsoil. Pemberian dosis tersebut dianggap sudah mencukupi kebutuhan tanaman nilam. Hal ini ditunjukkan dengan adanya respon positif terhadap pertambahan jumlah cabang primer tanaman nilam Aceh klon Sidikalang. Manipulasi media tumbuh yang tepat adalah dengan membuat komposisi media yang dapat mempertahankan kelembaban tanah dalam waktu relatif lebih lama dan mampu menyediakan unsur hara bagi tanaman (Muliawati, 2001; Sarief, 1985). 
Percabangan sangat bergantung pada faktor-faktor yang menguntungkan pertumbuhan vegetatif yang cepat, terutama kelembaban dan N yang cukup (Gardner et al. 1991). Pada periode umur 8 MST sampai dengan umur 12 MST terlihat bahwa perlakuan kombinasi 2,5 g pupuk hayati EMAS, dan $25 \mathrm{~g}$ pati pati beras (F) dapat memberikan hasil yang signifikan (Tabel 3). Pati beras mengandung unsur-unsur hara makro yang dibutuhkan tanaman diantaranya nitrogen $(\mathrm{N})$ yang berperan penting bagi pertumbuhan vegetatif tanaman (Gardner et al. 1991). Dalam hal ini pupuk hayati EMAS berperan aktif dalam menyerap nitrogen yang disediakan oleh tanah maupun pati beras sehingga lebih tersedia bagi tanaman.

Pupuk hayati EMAS dan pati beras mampu membantu pengadaan hara bagi tanaman, dan membantu mengurangi pencemaran lingkungan akibat penyebaran hara berlebihan yang tidak diserap tanaman, serta mampu meningkatkan efisiensi pemupukan. Pertumbuhan cabang sekunder bagi tanaman nilam berpengaruh positif terhadap berangkasan yang dihasilkan oleh tanaman, diduga dengan semakin baiknya pertumbuhan cabang-cabang baik cabang primer maupun cabang sekunder maka kemungkinan pertumbuhan daun semakin lebat. Daun merupakan organ target utama pad tanaman nilam sebagai tanaman penghasil minyak atsiri.

Luas daun terbaik dihasilkan oleh tanaman nilam yang ditanam pada media tanam subsoil yang diberi 2,5 g pupuk hayati EMAS dan $25 \mathrm{~g}$ pati beras (perlakuan F). Hal ini menunjukkan bahwa media tanam yang digunakan telah mampu menyuplai hara bagi tanaman terutama unsur $\mathrm{N}$ yang berperan untuk pembentukan luas daun menjadi lebih baik. Luas daun merupakan parameter pertumbuhan yang dapat menentukan laju fotosintesis per satuan tanaman (Sitompul dan Guritno, 1991). Sutedjo dan Kartasapoetra (1991) menambahkan bahwa fungsi $\mathrm{N}$ antara lain untuk meningkatkan pertumbuhan daun. Nitrogen dibutuhkan untuk membentuk senyawa penting seperti klorofil (Novizan, 2005).

Pertumbuhan daun pada tanaman akan mempengaruhi bobot segar dan bobot kering yang dihasilkan, terlebih daun merupakan komponen hasil yang penting bagi tanaman nilam. Media tanam pada perlakuan F (Tabel 4) menghasilkan bobot segar dan bobot kering tanaman tertinggi. Aktivitas fotosintesis yang tinggi di daun menjamin tersedianya fotosintat yang lebih banyak dan ini diperlukan untuk meningkatkan bobot segar tanaman yang lebih baik.

Bobot kering tanaman mencerminkan pola tanaman mengakumulasikan produk dari proses fotosintesis dan merupakan integrasi dengan faktor-faktor lingkungan lainnya. Menurut Gardner et al.(1991), bobot kering total dan bahan suling tanaman budidaya di lapangan merupakan akibat dari penimbunan hasil bersih

Tabel 3. Pengaruh Pati beras dan PHE pada Media Tanam Subsoil terhadap Pertambahan Jumlah Cabang Primer dan Jumlah Cabang Sekunder pada Umur 4 MST, 8 MST, dan 12 MST.

\begin{tabular}{clcccccc}
\hline \multirow{2}{*}{ Perlakuan } & \multicolumn{6}{c}{ Rata-rata pertambahan cabang primer (buah) } \\
\cline { 2 - 7 } & \multicolumn{2}{c}{ P MST } & \multicolumn{3}{c}{ 8 MST } & \multicolumn{2}{c}{ 12 MST } \\
\cline { 2 - 7 } Primer & Sekunder & \multicolumn{2}{c}{ Primer } & Sekunder & Primer & Sekunder \\
\hline $\mathrm{A}$ & $0.44 \mathrm{ab}$ & $0.56 \mathrm{a}$ & $0.44 \mathrm{ab}$ & $0.44 \mathrm{ab}$ & $0.33 \mathrm{ab}$ & $1.22 \mathrm{abc}$ \\
$\mathrm{B}$ & $0.33 \mathrm{a}$ & $0.67 \mathrm{ab}$ & $0.33 \mathrm{a}$ & $0.33 \mathrm{a}$ & $0.22 \mathrm{a}$ & $0.78 \mathrm{a}$ \\
$\mathrm{C}$ & $0.67 \mathrm{bcd}$ & $0.67 \mathrm{ab}$ & $0.67 \mathrm{ab}$ & $0.33 \mathrm{a}$ & $0.33 \mathrm{ab}$ & $0.89 \mathrm{ab}$ \\
$\mathrm{D}$ & $0.78 \mathrm{cde}$ & $0.78 \mathrm{abc}$ & $0.44 \mathrm{ab}$ & $0.33 \mathrm{a}$ & $0.33 \mathrm{ab}$ & $0.89 \mathrm{ab}$ \\
$\mathrm{E}$ & $0.56 \mathrm{abc}$ & $0.78 \mathrm{abc}$ & $0.56 \mathrm{ab}$ & $0.44 \mathrm{ab}$ & $0.44 \mathrm{abc}$ & $0.89 \mathrm{ab}$ \\
$\mathrm{F}$ & $0.78 \mathrm{cde}$ & $1.00 \mathrm{c}$ & $1.00 \mathrm{~b}$ & $0.67 \mathrm{~b}$ & $0.67 \mathrm{c}$ & $1.78 \mathrm{e}$ \\
$\mathrm{G}$ & $0.56 \mathrm{abc}$ & $0.89 \mathrm{bc}$ & $0.56 \mathrm{ab}$ & $0.44 \mathrm{ab}$ & $0.56 \mathrm{bc}$ & $1.33 \mathrm{bcd}$ \\
$\mathrm{H}$ & $0.44 \mathrm{ab}$ & $0.89 \mathrm{bc}$ & $0.44 \mathrm{ab}$ & $0.67 \mathrm{~b}$ & $0.56 \mathrm{bc}$ & $1.44 \mathrm{cde}$ \\
$\mathrm{I}$ & $0.78 \mathrm{cde}$ & $0.89 \mathrm{bc}$ & $0.78 \mathrm{ab}$ & $0.67 \mathrm{~b}$ & $0.56 \mathrm{bc}$ & $1.67 \mathrm{cde}$ \\
J & $1.00 \mathrm{e}$ & $0.78 \mathrm{abc}$ & $0.56 \mathrm{ab}$ & $0.56 \mathrm{ab}$ & $0.33 \mathrm{ab}$ & $1.33 \mathrm{bcd}$ \\
K & $0.89 \mathrm{de}$ & $1.00 \mathrm{c}$ & $0.44 \mathrm{ab}$ & $0.67 \mathrm{~b}$ & $0.44 \mathrm{abc}$ & $1.33 \mathrm{bcd}$ \\
\hline
\end{tabular}

Keterangan : Nilai rata-rata perlakuan yang ditandai dengan huruf yang sama pada kolom yang sama tidak berbeda nyata berdasarkan Uji Jarak Berganda Duncan pada taraf nyata 5\%, ; MST = Minggu Setelah Tanam $;$ PHE = Pupuk Hayati EMAS 
asimilasi $\mathrm{CO}_{2}$ sepanjang musim pertumbuhan. Produksi tanaman biasanya lebih akurat dinyatakan dengan ukuran bobot kering daripada dengan bobot basah, karena bobot basah sangat dipengaruhi oleh kondisi kelembaban. Lestari et al. (2008) menyatakan bahwa bobot basah tanaman dapat menunjukkan aktivitas metabolisme tanaman dan nilai bobot basah tanaman dipengaruhi oleh kandungan air jaringan, unsur hara dan hasil metabolisme.

Tabel 4. Pengaruh Pati Beras dan PHE pada Media Tanam Subsoil terhadap Luas Daun, Bobot Segar Tanaman, Bobot Kering Tanaman pada 12 MST

\begin{tabular}{cccc}
\hline Perlakuan & $\begin{array}{c}\text { Luas Daun } \\
\left(\mathbf{c m}^{2}\right)\end{array}$ & $\begin{array}{c}\text { Bobot } \\
\text { Segar } \\
\text { Tanaman } \\
\mathbf{( g )}\end{array}$ & $\begin{array}{c}\text { Bobot } \\
\text { Kering } \\
\text { Tanaman } \\
\mathbf{( g )}\end{array}$ \\
\hline $\mathrm{A}$ & $232.11 \mathrm{a}$ & $87.29 \mathrm{c}$ & $5.67 \mathrm{ab}$ \\
$\mathrm{B}$ & $219.81 \mathrm{a}$ & $74.24 \mathrm{a}$ & $5.45 \mathrm{a}$ \\
$\mathrm{C}$ & $222.47 \mathrm{a}$ & $77.33 \mathrm{ab}$ & $5.50 \mathrm{ab}$ \\
$\mathrm{D}$ & $237.28 \mathrm{a}$ & $78.40 \mathrm{ab}$ & $5.46 \mathrm{a}$ \\
$\mathrm{E}$ & $229.59 \mathrm{a}$ & $81.22 \mathrm{~b}$ & $5.93 \mathrm{abc}$ \\
$\mathrm{F}$ & $300.41 \mathrm{~d}$ & $103.86 \mathrm{e}$ & $8.77 \mathrm{e}$ \\
$\mathrm{G}$ & $276.73 \mathrm{bc}$ & $88.94 \mathrm{c}$ & $6.79 \mathrm{abcd}$ \\
$\mathrm{H}$ & $26.16 \mathrm{~b}$ & $89.40 \mathrm{c}$ & $6.94 \mathrm{bcd}$ \\
$\mathrm{I}$ & $287.02 \mathrm{~cd}$ & $98.60 \mathrm{de}$ & $7.56 \mathrm{de}$ \\
$\mathrm{J}$ & $287.54 \mathrm{~cd}$ & $96.51 \mathrm{~d}$ & $7.14 \mathrm{~cd}$ \\
$\mathrm{~K}$ & $285.11 \mathrm{~cd}$ & $90.19 \mathrm{c}$ & $6.93 \mathrm{bcd}$ \\
\hline
\end{tabular}

Keterangan: Nilai rata-rata perlakuan yang ditandai dengan huruf yang sama pada kolom yang sama tidak berbeda nyata berdasarkan Uji Jarak Berganda Duncan pada taraf nyata $5 \%$.

MST = minggu setelah tanam

Tanaman nilam dapat tumbuh baik pada media tanam subsoil yang diberi pupuk hayati dan pati beras dengan dosis tertentu. Hal ini menunjukan bahwa campuran media tanam tersebut dapat menggantikan media tanam topsoil sebagai media tanam nilam. Kandungan hara pada media tanam memiliki peranan penting dalam pertumbuhan tanaman. Unsur hara merupakan salah satu faktor eksternal yang menunjang pertumbuhan dan perkembangan tanaman. Kombinasi pupuk hayati dan pati beras pada media tanam subsoil dianggap sudah cukup menyediakan hara bagi tanaman untuk melakukan proses fotosintesis. Proses fotosintesis menghasilkan fotosintat yang mempengaruhi proses pembentukan organ tanaman daun dan akar yang kemudian menghasilkan produksi bahan kering (Sitompul dan Guritno, 1995).

\section{Kesimpulan}

1. Kombinasi dosis pati beras dan pupuk hayati pada media tanam subsoil memberikan pengaruh terhadap pertumbuhan tanaman nilam aceh (Pogostemon cablin Benth.) klon Sidikalang pada pertambahan tinggi, pertambahan jumlah daun, pertambahan jumlah cabang, luas daun, dan bobot kering tanaman.

2. Penerapan kombinasi dosis $25 \mathrm{~g}$ pati beras dan PHE 2,5 g pada media tanam subsoil menghasilkan pengaruh yang paling baik terhadap pertambahan tinggi, pertambahan jumlah daun, pertambahan cabang, luas daun, bobot segar tanaman, bobot kering tanaman, dan bobot kering akar tanaman nilam asal setek.

\section{Daftar Pustaka}

Erwiyono, R. 2005. Alasan media tanam tanah di pembibitan perlu dicampur pasir dan pupuk kandang. Warta Pusat Penelitian Tanaman Perkebunan Indonesia. 21 (3) : 129-135.

Gardner, F. P., R. Brent Pearce, Roger L. Mitchell. 1991. Fisiologi Tanaman Budidaya. Diterjemahkan oleh : Herawati Susilo. Penerbit Universitas Indonesia. Jakarta.

Hakim, M. 2013. Kelapa Sawit: Teknis Agronomis \& Manajemen. Jakarta: Media Perkebunan.

Hartatik, Wiwik, Husnain, dan Ladiyani R. Widowati. 2015. Peranan pupuk organik dalam peningkatan produktivitas tanah dan tanaman. Jurnal Sumberdaya Lahan Vol. 9 No. 2, Desember: 107-120.

Hardjowigeno S. 2003. Ilmu Tanah. Jakarta: Akademika Pressindo

Hidayat, T. C., G. Simangunsong, L. Eka, dan Y. H. Iman. 2007. Pemanfaatan berbagai limbah pertanian untuk pembenah media tanam bibit kelapa sawit. Jurnal Penelitian Kelapa Sawit PPKS. Medan.

Lestari, G.W, Solichatun, dan Sugiyarto. 2008. Pertumbuhan, kandungan klorofil, dan laju respirasi tanaman garut (Maranta arundinacea L.) setelah pemberian asam giberelat $\left(\mathrm{GA}_{3}\right)$. Bioteknologi. 5(1):1-9.

Lestariningsih, A. 2012. Meramu Media Tanam Untuk Pembibitan. Cahaya Atma Pustaka. Yogyakarta. 
Martin, A.B, M. Same, W. Indrawati. 2015. Pengaruh media pembibitan pada pertumbuhan setek lada (Piper nigrum L.). Jurnal AIP Volume 3 No. 2 Hal : 94-107.

Muliawati, E. S. 2001. Kajian tingkat serapan hara, pertumbuhan dan produksi sambiloto (Androgaphis paniculata Ness.) pada beberapa komposisi media tanam dan tingkat pengairan. Prosiding Simposium Nasional II Tumbuhan Obat dan Aromatik. APINMAP. Bogor, 8-10 Agustus 2001.

Novizan. 2005. Petunjuk Pemupukan yang Efektif. Agromedia Pustaka. Jakarta. Hal 81-83.

Nuryani, Y. 2006. Budidaya Tanaman Nilam (Pogostemon cablin Benth.). Balai Penelitian Tanaman Rempah dan Aromatik.

Nuryani, Y., Emmyzar, MS dan A. Wahyudi. 2007. Nilam Perbenihan dan Budidaya Pendukung Varietas Unggul. Penerbit Pusat Penelitian dan Pengembangan Perkebunan. Bogor.

PT. Bio Industri Nusantara. 2014. Tersedia online pada http://ptbionusa.co.id/webbaru/ wp-content/uploads/2016/12/BROSUREMAS.pdf. Diakses 11 Desember 2017.

Sarief, E. S. 1985. Konservasi Tanah dan Air. Bandung: Pustaka Buana.

Simanungkalit, R.D.M., A.S Didi, S.Rasti, S.
Diah, S. Wiwik. 2006. Pupuk Organik dan Pupuk Hayati Organic Fertilizer and Biofertilizer. Balai Besar Penelitian dan Pengembangan Sumberdaya Lahan Pertanian. Jawa Barat.

Siregar, H.M. 2000. Upaya meningkatkan produktivitas pada budidaya tempuyung (Sonchus arvensis L.). Gakuryoku 6 (2): 92-95.

Sitio, Y, G. Wijana, I.G.N. Raka. 2015. Pemanfaatan tandan kosong kelapa sawit dan pupuk nitrogen sebagai substitusi top soil terhadap pertumbuhan bibit kelapa sawit (Elaeis guineensis Jacq.) periode pre-nursery. E-Jurnal Agroekoteknologi Tropika Vol. 4, No. 4, Oktober 2015. Pp:264-273.

Sitompul S.M. dan Bambang Guritno. 1995. Analisis Pertumbuhan Tanaman. Gajah Mada University Press. Yogyakarta. Hal 113-114.

Sutedjo, M.M., dan Kartasapoetra 1999. Pupuk dan Cara Pemupukan. Rineka Cipta. Jakarta

Suwahyono, U..2011. Petunjuk Praktis Penggunaan Pupuk Organik Secara Efektif dan Efisien. Penebar Swadaya. Jakarta.

Zulfitri. 2005, Analisis varietas dan polybag terhadap pertumbuhan serta hasil cabai (Capsicum annum L.) Sistem Hidroponik. BULETIN Penelitian (08). Universitas Mercu Buana. Jakarta. 